\title{
INTRODUCTION \\ Thoracolumbar anterior spine surgery: contemporary techniques and outcomes
}

\author{
Paul Park, MD, ${ }^{1}$ Juan Uribe, MD, ${ }^{2}$ Tokumi Kanemura, MD, ${ }^{3}$ and Dean Chou, MD ${ }^{4}$ \\ 'Department of Neurosurgery, University of Michigan, Ann Arbor, Michigan; ${ }^{2}$ Barrow Neurological Institute, Phoenix, Arizona; \\ ${ }^{3}$ Spine Center, Konan Kosei Hospital, Konan, Aichi, Japan; and ${ }^{4}$ Department of Neurosurgery, University of California, San \\ Francisco, California
}

$\mathrm{S}$ PINAL pathologies are varied and encompass a broad spectrum of diseases, including degenerative conditions and those related to deformity, trauma, and infection. For certain conditions, the most direct and efficacious treatment requires an anterior approach to the spine. Although anterior spinal surgery is not new, adoption of anterior approaches has been limited by the perceived morbidity of these techniques compared to posterior approaches and by the limited approach options for anterior procedures. In recent years, however, there has been new insight into the advantages of anterior surgery for improving alignment as well as evolution of new techniques and technologies.

This issue of Neurosurgical Focus presents an array of articles focusing on contemporary techniques, outcomes, complications, and novel applications of anterior approaches for spine surgery. Topics ranging from the efficacy of indirect decompression to outcomes for back pain after anterior lumbar fusion are included. There are also several articles evaluating complications of spinal procedures, including those more specific to anterior spinal surgery. In addition, studies of minimally invasive approaches, such as single-position prone lateral fusion and the use of navigation for lateral lumbar interbody fusion, are presented.
The procedures highlighted in this issue of Neurosurgical Focus broaden the scope of possibilities for the anterior approach, enabling spine surgeons to minimize surgical morbidity while providing state-of-the-art care for patients who will most benefit from improved alignment and other advantages of thoracolumbar anterior spine surgery.

https://thejns.org/doi/abs/10.3171/2020.6.FOCUS20568

\section{Disclosures}

Dr. Park reports being a consultant for Globus and NuVasive, receiving royalties from Globus, and receiving support of nonstudy-related clinical or research efforts from ISSG and DePuy. Dr. Uribe reports being a consultant for Misonix and NuVasive and receiving royalties from, having direct stock ownership of, and receiving support of non-study-related clinical or research efforts from NuVasive. Dr. Kanemura reports being a consultant for Medtronic, Zimmer Biomet, and NuVasive. Dr. Chou reports being a consultant for and receiving royalties from Globus.

\section{Correspondence}

Paul Park:ppark@umich.edu. 